\title{
Infection following operations on the central nervous system: deconstructing the myth of the sterile field
}

\author{
Brian P. Walcott, M.D., Navid Redjal, M.D., and Jean-Valery C. E. Coumans, M.D. \\ Department of Neurosurgery, Massachusetts General Hospital and Harvard Medical School, Boston, \\ Massachusetts
}

\begin{abstract}
Neurosurgical patients are at a high risk for infectious sequelae following operations. For neurosurgery in particular, the risk of surgical site infection has a unique implication given the proximity of the CSF and the CNS. Patient factors contribute to some degree; for example, cancer and trauma are often associated with impaired nutritional status, known risk factors for infection. Additionally, care-based factors for infection must also be considered, such as the length of surgery, the administration of steroids, and tissue devascularization (such as a craniotomy bone flap). When postoperative infection does occur, attention is commonly focused on potential lapses in surgical "sterility." Evidence suggests that the surgical field is not free of microorganisms. The authors propose a paradigm shift in the nomenclature of the surgical field from "sterile" to "clean." Continued efforts aimed at optimizing immune capacity and host defenses to combat potential infection are warranted.
\end{abstract}

(http://thejns.org/doi/abs/10.3171/2012.8.FOCUS12245)

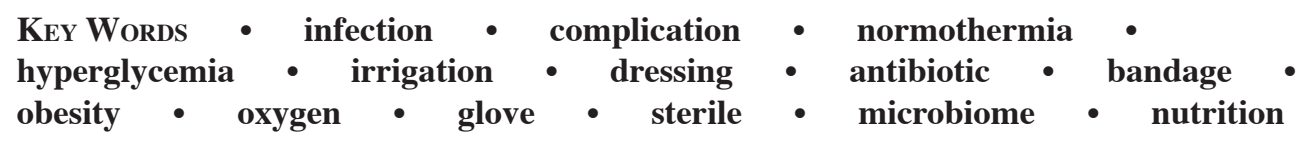

$\mathrm{T}$ HE world comprises innumerable bacterial species, all having highly evolved genomes that enable them to occupy specialized niches. Even when we limit our analysis of bacteria to the human body, there is a vast diversity of environments, each with a specific microbiome. ${ }^{74}$ The human skin alone exhibits regional microbiome differences, and the NIH has recently launched a $\$ 140$ million dollar project aimed at characterizing 3000 reference genomes isolated from various body sites (http://www.hmpdacc.org/reference_genomes/reference_genomes.php). Given the distribution of the microbiome, one might expect a difference in the susceptibility and the type of surgical wound infection based on the local bacterial population alone. Indeed, data of surgical site infections suggest a correlation between surgery site and infectious organism. ${ }^{106}$ Therefore, surgery can be viewed not only as a disruption in the homeostatic state of host defenses, but also as a disruption in the normal activity of regionally specific bacteria. It is only when the balance of host defenses and the expression of bacterial virulence factors is altered that a clinical state of infection can exist..$^{56,62,64}$ Humans and bacteria typically exist in either a state of mutualism or commensalism; there- fore we must recognize the existence of bacteria, even in the surgical field.

\section{Clean, but Not Sterile}

It is impossible to eradicate all microbes from the surgical field. Ultrastructurally, the skin surface contains crevices, including the sweat glands, that are incompletely accessible to commonly used skin preparation solutions or scrub techniques. ${ }^{65}$ The degree to which our standard surgical skin preparation fails to sterilize the surgical field is highlighted in a recent publication by Shiono et al. ${ }^{83}$ In this study, the authors obtained cultures at various time points during spine deformity operations. They demonstrated that $31 \%$ of skin cultures were positive immediately after patient skin cleansing with a povidone-iodine scrub solution. Not surprisingly, $25 \%$ of wound cultures were positive immediately after the initial exposure. This suggests that bacteria penetrate the wound at the time of the initial surgical exposure. It is likely that most wound infections are the result of direct contamination with the local microbiome, although several other sources of bacteria exist in the operating room. "Lapses" in sterile technique, such as the use of contaminated in- 
struments and touching of unclean surfaces, certainly do exist and may introduce a greater inoculum and different microorganisms to the surgical field.

\section{Evidence That We Are Not Alone}

The theory of surgical asepsis was introduced more than 100 years ago. ${ }^{8}$ Since then, great strides have been made in decreasing bacterial presence in surgical wounds. Technological advancements such as the use of continuous video recording of surgical technique have been used to identify obvious breaks in sterile technique, ${ }^{11}$ but total surgical field sterility is not achievable. From the moment a surgeon performs the ritualistic surgical scrub, bacteria are present in the water. ${ }^{17,42,58,77}$ Swab studies and settle plate techniques demonstrate that microbes abound in the operating room. Even the air itself contains aerosolized microorganisms. During routine joint arthroplasty operations, a standard particle analyzer identified an average of 1786 colony forming units (primarily gram-positive cocci) from the air over a 10 -minute capture period. ${ }^{90}$ Other studies have used air sampler/settle plate techniques to assess the effect of different variables during simulated lumbar discectomies on microbe prevalence. ${ }^{102}$ During simulated operations, more than half of the samples in groups using the operative microscope or headlamp and loupes demonstrated bacterial growth (mainly coagulase negative Staphylococcus), significantly more than the control group. ${ }^{102}$ The efficacy of routine cleaning of surgical loupes, headlamps, and operating microscopes on the quantity of aerosolized microbes is not known, yet it is a minimal resource and no-risk intervention that may decrease the wound inoculum. With airborne bacteria, it is not surprising that many should end up on the "sterile" field.

Nearly all surgical gowns used in the operating room contain the presence of microorganisms. Systematic swab studies have demonstrated varying degrees of areas of cleanliness at the end of spinal operations. The presence of bacteria has been demonstrated to be lowest in the region between the chest and operative field, indicating that this may be the cleanest area of the surgical gown. ${ }^{11}$ The applicability of this statement must take into consideration the type of operation being performed, because the ergonomic positions used to perform a spinal operation are distinctly different from those used when performing a retrosigmoid craniotomy. These surgical positioning factors may influence a surgical gown's regional propensity for cleanliness.

The operating microscope drape is also frequently inhabited by microorganisms during operations. While negative control drapes have demonstrated no bacterial growth, microscope drapes used in spine operations have been shown to approach $100 \%$ contamination. ${ }^{12}$ By using swabs obtained from different regions of the microscope drape, investigators in the study by Bible et al. ${ }^{12}$ attempted to quantify regions of relative cleanliness. The "dirtiest" regions included the shafts of the optic eyepieces for the primary surgeon, the forehead portion on both viewing stations, and the overhead portion of the drape. This was hypothesized to occur due to inadvertent touching of the sterile portion of the drape by the surgeon. Interventions such as changing gloves after eyepiece adjustment and avoiding handling anything above the eyepieces may decrease wound inoculum, although these measures have not been evaluated.

Information regarding the relative cleanliness of other areas of the surgical field is less well known. For example, light handle covers are potential sources for inadvertent contamination, yet a literature search reveals no information other than data from dental operations. Other potential high-risk areas exist in the surgical field, such as frameless stereotactic reference systems, because they traverse layers of the surgical drapes. There is also a paucity of data regarding the sterility of methods to drape the intraoperative CT or MRI scanners. Information from other intraoperative imaging techniques such as fluoroscopy can be extrapolated in these cases for estimation purposes, although it is not implied to be applicable. In a swab study, nearly all the drapes from a C-arm fluoroscopy machine were positive for bacterial growth after being used in a spinal operation. ${ }^{13}$ As the number of intraoperative imaging operations increases, it is important to optimize and standardize draping to minimize bacterial inoculum.

\section{Preoperative Interventions}

While the great majority of surgical wounds are contaminated, infections are still a relatively rare event. This indicates that the vast majority of bacteria are successfully cleared by the host. Multiple actions taken by the surgeon can be aimed at reducing the bacterial inoculum, which in turn may prevent the development of infection. Other actions taken by the surgeon can be aimed at optimizing host defense, something that is potentially the most significant aspect preventing surgically related infection (Table 1).

\section{Preoperative Factors}

The avoidance of surgical site infection begins in the preoperative period with several modifiable risk factors. The complex interplay between nutritional status and immune function cannot be understated. ${ }^{31,47}$ In a series of patients undergoing total joint arthroplasty, preoperative serum albumin levels $<3.5 \mathrm{~g} / \mathrm{dl}$ (controversially used as a surrogate marker of nutritional status) were associated with a 7-times greater frequency of wound complication. ${ }^{31}$ For this reason, patients scheduled for elective or selective surgery could benefit from screening for impaired nutritional status. Identifying cachectic patients with malignancy or advanced age may allow for generalized nutritional optimization prior to surgery, thereby avoiding a known risk factor for infection.

In addition to optimizing the general nutritional state of patients prior to surgery, implementation of so-called immunonutrition supplements may improve rates of surgical infection. Preoperative supplementation with omega-3 fatty acids, arginine, glutamine, and nucleotides has been shown to boost immune function in clinical trials of surgical patients. Evidence for this benefit resides in their beneficial effect on known biomarkers of immune capacity and function, such as HLA-DR epitopes on monocytes and serum levels of interleukin- 6 in high-risk surgical patients. ${ }^{66,95}$ Healthy volunteer studies have also 


\section{Neurosurgical infection prevention}

\section{TABLE 1: Common infection prevention strategies}

\begin{tabular}{|c|c|c|c|}
\hline Timing & Focus & Intervention & $\begin{array}{l}\text { Level of } \\
\text { Evidence* }^{*}\end{array}$ \\
\hline preop & antibiotics & administration of antibiotics in the 2 hours before surgery reduces the risk of wound infection ${ }^{18}$ & ॥ \\
\hline preop & checklist & $\begin{array}{l}\text { implementation of the checklist was associated w/ concomitant reductions in the rates of death \& complications } \\
\text { (including surgical site infection) among patients at least } 16 \text { yrs of age who were undergoing noncardiac surgery }{ }^{41}\end{array}$ & II \\
\hline \multirow[t]{2}{*}{ preop } & skin prep & $\begin{array}{l}\text { there is insufficient research examining the effects of preoperative skin antiseptics to allow conclusions to be drawn } \\
\text { regarding their comparative effects on postop surgical wound infections; } 22\end{array}$ & I \\
\hline & & there was no evidence of a benefit in 4 trials associated w/ the use of iodophor-impregnated drapes ${ }^{22}$ & I \\
\hline \multirow[t]{2}{*}{ intraop } & gloving & $\begin{array}{l}\text { there is no direct evidence that additional glove protection worn by the surgical team reduces surgical site infections } \\
\text { in patients, but the review has insufficient power for this outcome; } 92\end{array}$ & I \\
\hline & & perforation indicator systems result in significantly more innermost glove perforations being detected during surgery ${ }^{92}$ & 1 \\
\hline intraop & antibiotics & $\begin{array}{l}\text { intraop redosing of cefazolin was associated w/ reduction in the overall risk for surgical site infection after cardiac sur- } \\
\text { gery } 108\end{array}$ & III \\
\hline \multirow[t]{2}{*}{ postop } & antibiotics & $\begin{array}{l}\text { antibiotics administered beyond } 48 \text { hours after cardiac surgery are ineffective in reducing surgical site infection \& in- } \\
\text { crease antimicrobial resistance; } 37\end{array}$ & III \\
\hline & & prophylactic antimicrobials should be discontinued within 24 hours after the end of surgery ${ }^{15}$ & V \\
\hline
\end{tabular}

* Level of evidence assessed by the Oxford Centre for Evidence-Based Medicine 2011 Levels of Evidence (http://www.cebm.net/index.aspx?0=5653).

been performed that have demonstrated the beneficial effect of immune-boosting supplementation on experimental models of surgical wound healing and immune function. , 46 The most compelling evidence for their routine use in surgical patients comes from prospective, randomized, double-blind trials in which preoperative supplementation with arginine, omega-3 fatty acids, and dietary nucleotides resulted in a significantly reduced incidence of postoperative infection. ${ }^{20,86}$

Overnutrition of the patient is also a concern to the neurosurgeon. Obesity is associated with an increased incidence of infection in patients undergoing spinal arthrodesis surgery. ${ }^{61}$ Specifically, the distribution of central obesity is more predictive of surgical site infection than body mass index alone. This can be measured on preoperative imaging by the length from the skin to the lamina distance at the L-4 level. ${ }^{61}$ Other methods to evaluate central obesity include the $\mathrm{W}$-index (measured as the skin-spinous process distance to the anterior vertebral body-spinous process distance ratio). The influence of subcutaneous fat on surgical site infection is likely multifactorial, with increased operative difficulty, longer operative time, impaired tissue perfusion, higher proportion of diabetes mellitus, and impaired postoperative mobility contributing to varying degrees. Obesity may also impair tissue penetration of prophylactic antibiotics in a dose-independent fashion, limiting their efficacy in preventing surgical infections. ${ }^{97}$ Facilitating preoperative weight loss in obese and superobese patients in the preoperative setting is indicated not only for general health purposes, but it has also been shown to decrease surgical complications. ${ }^{3,89}$

Other techniques for infection risk reduction in the preoperative period relate to reducing bacterial flora in the patient. Several studies have examined the influence of preoperative whole-body bathing with chlorhexidine or other wash products on surgical infection; a systematic review of 7 trials encompassing over 10,000 operations provides no clear evidence of benefit. ${ }^{101}$ However, direct efforts to eliminate $S$. aureus nasal carriage in the preop- erative setting have been shown to be effective in decreasing surgical site infections in cardiac surgery patients. ${ }^{81}$ Efforts at evaluating the effect of surveillance and eradication of bacterial carriage in a neurosurgical-specific population have not yet been undertaken.

Another potential opportunity for preoperative intervention resides in determining the optimal order of surgical cases performed in a day by any particular surgeon. It has been shown that procedures performed later in the day carry a higher risk for postoperative infection. ${ }^{33}$ Factors postulated to contribute to this phenomenon include the progressive deterioration of operating room cleanliness as the day progresses, cross contamination between health care providers during the course of the day, the use of flash sterilization for surgical instruments, and even nursing shift changes. ${ }^{33}$ It should be noted that none of these factors has been validated in prospective trials. Scheduling patients that are anticipated to undergo longer operations and who possesses more patient-centered risk factors for infection to undergo surgery first in the day is a systems-based intervention that may be beneficial to overall infection rates. Given the limitations of study design, it is unlikely that this hypothesis could be practically evaluated.

\section{Operative Preparation}

While infection avoidance begins with optimizing preoperative host defenses, operations themselves are the setting in which bacteria infiltrate into surgical wounds and therefore play a key role in the balance between bacterial contamination and infection. Operations begin with both patient and surgeon skin preparation to reduce microbial load. While one may assume that decreased microbial load, particularly on the patient's skin, would be an independent risk factor for infection following neurosurgical operations, a prospective study found that microbial counts from preoperative (postpreparation) skin cultures were not associated with surgical site infec- 
tions. ${ }^{19}$ In that study, obesity, duration of surgery, and age were independent statistically significant risk factors for infection following craniotomy. ${ }^{19}$ Although there is little controversy as to whether skin preparation is effective compared with no treatment at all, this finding supports the premise that bacteria abound in the surgical field even after patient skin cleansing. It also gives support to the notion that patient-centered variability in host defense plays a significant role in the development of infection in the setting of bacterial contamination. Additionally, there may be features of the skin preparation solution beyond its initial bactericidal effect that are unique to the durability and duration of its action. ${ }^{30,44}$ There are high quality data that preoperative cleansing with a chlorhexidine-alcohol solution is superior to povidone-iodine for preventing surgical site infections. ${ }^{21}$ These data provide evidence that differences in patient skin preparation do matter and directly contribute to the incidence of postoperative infections. The absolute microbial load just prior to incision may not be as influential as the duration of action of the antibacterial agent.

Another major component of patient skin preparation is the decision regarding the amount of hair removal. Practice patterns vary from wide hair removal from the scalp to no hair removal at all. In a large neurosurgical series, the practice of hair removal did not lower the risk of surgical wound infection. ${ }^{104}$ In a review of more generalized surgical procedures,${ }^{94}$ there was no difference found in surgical site infections for those with hair removed prior to surgery compared with those who did not. When hair is removed, there is evidence that using a razor increases the rate of surgical wound infection when compared with using electric clipper devices, ${ }^{1,94}$ likely related to damage that a razor produces in the epidermis more so than electric clippers. Razors should not be used to remove hair in neurosurgical patients. Emphasis must also be placed on having electric clippers accessible to surgeons requiring hair removal when performing bedside procedures, such as ventriculostomy.

In addition to patient skin preparation, the surgeon's hand scrub is one of the most ritualistic portions of an operation and is routinely performed to prevent surgical site infection. Even though the surgeon's skin does not come into contact with the surgical field under ideal conditions, there is potential to transmit microbes through defects in surgical gowns or gloves. Therefore, the hypothesis exists that reducing the surgeon's microbial load can limit the potential for microbe transmission to the surgical field if defects exist. Methods of surgical scrub generally include the use of alcohol rubs or aqueous scrubs. Alcohol rubs are at least equivalent to aqueous scrubbing, ${ }^{69}$ yet no superiority of one method over the other exists. ${ }^{93}$ Because the alcohol-based rubs are potentially better tolerated and can be performed in less time, compliance may be improved. Similar to patient skin preparation, evidence from multiple studies suggests that chlorhexidine-based scrubs are more effective than povidone-iodine-based scrubs..$^{93}$ There exists no Class I or II evidence regarding the efficacy of scrub duration or mechanical adjuncts (such as brushes and sponges). ${ }^{93}$

The air in the operating room itself has the potential to contribute to surgical site infection given the known presence of aerosolized microbes. In high-risk, high-consequence surgical settings, joint replacement surgeons have turned to the concept of ultraclean air in the operating room to mitigate this factor. Using "space suits" and laminar airflow, the amount of microbes that are aerosolized can be reduced. In an analysis of thousands of operations, those performed in ultraclean air had a substantially reduced incidence of joint and major wound infection. ${ }^{52,53}$ Even the concept of ultraviolet light to kill aerosolized microbes has been proposed, yet is recommended against due to the documented potential health risks to surgical personnel. ${ }^{25}$

As part of the patient preparation on the day of an operation, preoperative antibiotics are administered just prior to the incision to reduce the risk of subsequent surgical site infection. This practice has been widely adopted and is even recognized as a core component in surgical "time-out" checklists as a testament to the magnitude of their efficacy. ${ }^{14,15,18,41}$ The timing of administration is optimally within 60 minutes before skin incision. ${ }^{16}$

Surgical draping follows skin preparation and is one of the most variable practices in neurosurgery. The common goal is to provide a barrier between areas that have not undergone skin preparation with those that have, thereby establishing the surgical field.

Adhesive drapes applied directly to the surgical site have been the subject of debate with regards to surgical site infection. In neurosurgery, adhesive drapes may not even be technically possible given the presence or absence of hair. When looking at studies that compared the effect of adhesive drape with no adhesive drape, a significantly higher proportion of patients in the adhesive drape group developed a surgical site infection. ${ }^{100}$ Therefore, it appears that there is at least preliminary evidence that adhesive drapes may increase infection rates.

\section{Intraoperative Interventions}

\section{Antibiotic Administration}

Given that it is known that bacteria are introduced into wounds by the act of surgery, certain actions taken by the surgeon can minimize the bacterial inoculum experienced by patients. Local antibiotics, in addition to systemically delivered prophylactic antibiotics, are a promising and low-risk intervention. In a large cohort of neurosurgical patients undergoing implantation of hardware, the infection rate was lowest (effectively zero) in those treated with local neomycin/polymixin treatment in addition to systemic antibiotics. ${ }^{63}$

The old adage that "the solution to pollution is dilution" may hold true, although caveats exist. Local wound irrigation, particularly with detergent additives, is effective at cleansing surgical wounds. ${ }^{5}$ The aim of local wound irrigation is to remove, rather than kill, bacteria. While the volume of irrigation appears to be an important factor, the optimal volume or duration of irrigation is not known. In fact, high-pressure lavage has been shown to damage bone structure and disrupt soft tissue, possibly causing deeper penetration and retention of harmful 
bacteria. ${ }^{40}$ Therefore, low-pressure lavage, combined with detergent or antibiotic agents, is indicated in the intraoperative care of routine surgical wounds.

As neurosurgical operations progress in length, the cumulative time possible for bacteria to mount an invasion accumulates. Some of the initial interventions such as preoperative antibiotic dosing lose their efficacy in a pattern related to the particular pharmacokinetics of the antibiotic administered. ${ }^{45,59}$ Therefore, redosing antibiotics in long-duration procedures at routine intervals is recommended to maintain antimicrobial action at the internal tissue level. ${ }^{108}$ Automation with computerized prompts in the anesthesia record system is efficacious in increasing compliance with this redosing and should be routinely employed. ${ }^{88,107}$ Perioperative antibiotics are therefore those that are administered immediately before surgery, during surgery, and following an operation, and their proven efficacy is sufficient enough to warrant systems-based approaches to ensure timely consideration and dosing in all 3 time periods.

\section{Additional Gloving}

Other aspects of long duration procedures have implications given the mechanical wear and tear on surgical gowns, draping, and gloves. Some surgeons have advocated for the changing of surgical gloves to a fresh pair just prior to handling implantable hardware as a means to decrease infection risk..$^{72}$ In theory, this does little to alter microbes that are already in the wound or microbes that are located on the surgical instruments, drapes, or surgical gown. Changing gloves prior to handling hardware may be effective in unknown ways, such as preventing the further introduction of bacteria as a result of occult perforations in surgical gloves. These perforations occur commonly in surgery and typically an hour after the initial incision. ${ }^{35}$ Perforations can be minuscule and require water leakage or air-inflation tests to detect. Perforation indicator systems result in better detection of these acquired defects. ${ }^{92}$ Double gloving can reduce perforations to the innermost glove, yet its efficacy to reduce surgical site infections has yet to be observed..$^{92}$ Procedures that place more mechanical stress on surgical gloves, such as instrumented spinal fusions, warrant consideration for more than 1 layer of glove or more robust material.

\section{Tissue Handling Techniques}

There are other less tangible aspects of neurosurgery that may predispose to infection, such as tissue handling techniques. Forceps destruction of skin edges, electrocautery, and retractor-related soft tissue ischemia are difficult to study, yet may be major determinants in preventing wound infection. Because the surgical incision is a controlled wound, surgeons must control the aspects that contribute to wound healing as much as possible in the patient's favor. ${ }^{84}$ The use of Bovie electrocautery is commonplace in neurosurgical operations, ${ }^{78}$ given its ease of use and efficiency in providing pinpoint hemostasis. The local tissue destruction caused by the Bovie impairs local blood flow and, in turn, the accessibility of the operative bed to the circulating immune system. The same can be said for other means of surgical hemostasis, such as bipolar cautery and radiofrequency ablation..$^{99,109}$ The formation of coagulated tissue in conjunction with impaired local immunity may predispose the patient to infection. Relatively few studies exist on the effects of Bovie electrocautery usage, yet their preliminary findings are important to consider. In a study of patients undergoing laparotomy, Bovie use increased the rate of postoperative infection. ${ }^{87}$ Adverse effects of excessive Bovie use were also noted with seroma formation following mastectomy. ${ }^{73}$ For patients undergoing median sternotomy, discriminate use of electrocautery decreased infection rates. ${ }^{67} \mathrm{~A}$ major confounding factor with these studies is the very tissue operated on. In highly vascularized tissue, such as the posterior spine, Bovie use does not appear to have adverse effects. ${ }^{48}$ Meanwhile, median sternotomy and craniotomy both entail the dissection of well-vascularlized soft tissue overlying a devascularized, approximated bone incision. Other hemostatic adjuncts must be considered as well (such as bone wax) that have been demonstrated to increase the rate of sternotomy infection and dehiscence..$^{39,55}$ New wax substitutes such as alkylene oxide copolymer bone hemostatic material are highly biocompatible, absorbed, and do not inhibit bone healing. ${ }^{57,103}$

\section{Local Tissue Perfusion and Oxygenation}

Although deliberate alteration of perfusion and oxygenation during neurosurgical operations is common to provide the goal of neural protection, ${ }^{34,50,68,96}$ there may be consequences from these manipulations in terms of postoperative infection rates. Physiologically, hypothermia induces peripheral vasoconstriction that reduces oxygen tension in the subcutaneous tissues. ${ }^{54,82}$ Because phagocytes and neutrophils require relatively high oxygen content for antimicrobial activity, 2,6,27 it has been postulated that artificial augmentation may improve surgical infection rates. In selected studies, intraoperative and postoperative high-concentration oxygen administration has been associated with a significant reduction in postoperative surgical wound infections..$^{9,32}$ Consistent with this hypothesis, maintenance of normothermia has also been associated with a reduction of surgical site infection. ${ }^{49}$ However, these studies were performed in a very small subgroup of patients undergoing colon surgery, making their applicability to the general neurosurgical population difficult. Follow-up studies have demonstrated that the use of induced perioperative high-oxygen delivery in a general surgical population does not reduce the overall incidence of surgical site infection. ${ }^{75}$ Further study is necessary in regional tissue oxygenation in the neurosurgical population, particularly considering the unique variable of neural protection.

\section{Wound Closure and Dressing Techniques}

At the conclusion of the procedure, most wounds are dressed with a bandage. This variable practice serves to aesthetically improve the patient's condition following surgery and to provide some barrier to further microbial invasion. Because the wound is not completely epithelial- 
ized for several days, ${ }^{84}$ there is some vulnerability to further bacterial infiltration, and whether a bandage prevents this infiltration is not proven. There is also a hypothesis that surgical dressings provide a milieu for accelerated bacterial growth.

In a large series of neurosurgical patients, antibiotic ointment was applied in lieu of a bandage with comparable infection rates to historical controls..$^{105}$ Other than gauze dressings, other options for dressing surgical wounds include the use of tissue adhesives such as octyl cyanoacrylate. In vitro experiments have demonstrated that octyl cyanoacrylate is an effective barrier to microbial penetration by gram-positive, gram-negative, and nonmotile species for at least 72 hours. ${ }^{10}$ It has also been widely used in neurosurgical spine practice with low infection rates. ${ }^{36}$ Other wound barriers include silver-impregnated dressings that have been used following lumbar fusion and are associated with a reduced incidence of infection. ${ }^{23}$

\section{Postoperative Interventions}

\section{Direct Antimicrobial Interventions}

Interventions in the period following an operation are necessary to reduce the incidence of surgical infections. Prolonged courses of antibiotics (beyond 24 hours postoperatively) are sometimes administered in a prophylactic fashion, yet evidence for the efficacy of this practice is lacking. In patients undergoing coronary artery bypass surgery, prolonged duration of prophylactic antibiotics was ineffective in reducing surgical site infection and also increased the incidence of antimicrobial resistance. ${ }^{37}$ Microbial resistance is a growing problem in both the community and the hospital setting; therefore antibiotics should be administered judiciously. ${ }^{79}$ Because most antibiotic resistance mechanisms are associated with a fitness cost of reduced bacterial growth rate, it is possible that susceptible bacteria will outcompete resistant bacteria if the selective pressure from antibiotics is reduced. ${ }^{4}$ Other "systemic" forms of antimicrobial treatment, such as daily chlorhexidine baths, have been shown to be effective in decreasing rates of methicillin-resistant $S$. aureus and Acinetobacter infection, in addition to lowering rates of catheter-related bloodstream infection. ${ }^{24}$ There may be elements to carefully extrapolate from this trauma population, given the sample size and power limitations of performing separate neurosurgical studies. For example, catheter-related bloodstream infections share a similar physical mechanism with external ventricular cathetersboth are indwelling conduits that traverse the skin. Introducing chlorhexidine into the daily postoperative bathing solution is safe, requires little additional resources, and has a proven efficacy in reducing infection in a high-risk intensive care population. ${ }^{24}$

\section{Optimizing Postoperative Host Defense}

Besides direct antimicrobial interventions, other surgeon-directed efforts at optimizing host defense in the postoperative setting are beneficial. Optimizing chronic health conditions such as diabetes mellitus is one prevalent subject of ongoing study. Elevated serum glucose directly impairs neutrophil ${ }^{28,71}$ and dendritic cell function, ${ }^{76}$ the major orchestrators of innate and adaptive immunity, respectively. In clinical trials, the use of perioperative continuous intravenous insulin infusion in diabetic patients undergoing open heart surgery reduced major infection and hospital cost. ${ }^{26}$ However, there are also drawbacks to intensive insulin therapy, such as episodes of hypoglycemia, increased length of hospital stay, and even possible effects on mortality. ${ }^{29}$ Evidence from a study of patients with brain tumors identified the duration of surgery as more important than blood glucose levels in the development of surgical site infection. ${ }^{38}$ There likely exists an as-yet-to-be-determined optimal protocol that maximizes the benefit of avoiding hyperglycemia associated with infection and avoiding episodes of hypoglycemia that can contribute to death. This is extremely difficult in the neurosurgical population, in which steroids are routinely administered (or are endogenously produced as part of their disease process) that can result in elevated serum glucose levels. ${ }^{70}$

Steroids themselves are immunosuppressive, and their use can predispose individuals to infection. This is true in the case of endogenous steroid production (Cushing disease $)^{80,98}$ and with exogenous steroid administration. ${ }^{43}$ It is possible that steroid administration may contribute to a negative synergy with patient pathophysiology and nutritional status, as observed in the setting of spinal operations for metastases. ${ }^{60}$

Judicious use of postoperative steroids may reduce wound infection rates, but randomization and accounting for covariates are difficult to accomplish in clinical trial design. Surveillance for postoperative wound infection is important in the immediate days following an operation. Additionally, some indolent organisms such as Proprionibacterium acnes can cause delayed surgical site infections,${ }^{51}$ highlighting the need for patient education prior to discharge from the hospital.

Because sufficiently powered studies require thousands of patients to identify even small differences in a heterogeneous population with an already low rate of infection, many of these hypotheses cannot be practically evaluated; however, their lack of proven benefit does not necessarily indicate lack of efficacy. ${ }^{85}$ Evaluating the cumulative and subspecialty surgical experience alike is important, because many of the infectious-related concepts already tested in clinical trials may have applicability to neurosurgical patients.

\section{Conclusions}

Any single infection in a neurosurgical patient represents the perturbation of balance between host defenses, virulence of the microbiome, and the inoculum experienced at the time of surgery. Efforts from the surgical team must be directed at each one of these fronts; the emphasis on any 1 factor should not lead to neglect of the others. Optimization of infection risk factors based on these principles can reduce the incidence of infection, thereby avoiding significant morbidity and mortality.

\section{Disclosure}

Dr. Walcott is supported by the Council of State Neurological Societies Socioeconomic Fellowship (2012-2013). 
Author contributions to the study and manuscript preparation include the following. Conception and design: all authors. Acquisition of data: Walcott, Coumans. Analysis and interpretation of data: Walcott, Coumans. Drafting the article: all authors. Critically revising the article: all authors. Reviewed submitted version of manuscript: all authors. Approved the final version of the manuscript on behalf of all authors: Walcott. Study supervision: Coumans.

\section{References}

1. Alexander JW, Fischer JE, Boyajian M, Palmquist J, Morris MJ: The influence of hair-removal methods on wound infections. Arch Surg 118:347-352, 1983

2. Allen DB, Maguire JJ, Mahdavian M, Wicke C, Marcocci L, Scheuenstuhl H, et al: Wound hypoxia and acidosis limit neutrophil bacterial killing mechanisms. Arch Surg 132:991-996, 1997

3. Alvarado R, Alami RS, Hsu G, Safadi BY, Sanchez BR, Morton JM, et al: The impact of preoperative weight loss in patients undergoing laparoscopic Roux-en-Y gastric bypass. Obes Surg 15:1282-1286, 2005

4. Andersson DI, Hughes D: Antibiotic resistance and its cost: is it possible to reverse resistance? Nat Rev Microbiol 8:260-271, 2010

5. Anglen JO: Wound irrigation in musculoskeletal injury. J Am Acad Orthop Surg 9:219-226, 2001

6. Babior BM: Oxygen-dependent microbial killing by phagocytes (first of two parts). N Engl J Med 298:659-668, 1978

7. Barbul A, Lazarou SA, Efron DT, Wasserkrug HL, Efron G: Arginine enhances wound healing and lymphocyte immune responses in humans. Surgery 108:331-337, 1990

8. Beck C: A Manual of the Modern Theory and Technique of Surgical Asepsis. Philadelphia: WB Saunders, 1895

9. Belda FJ, Aguilera L, García de la Asunción J, Alberti J, Vicente R, Ferrándiz L, et al: Supplemental perioperative oxygen and the risk of surgical wound infection: a randomized controlled trial. JAMA 294:2035-2042, 2005

10. Bhende S, Rothenburger S, Spangler DJ, Dito M: In vitro assessment of microbial barrier properties of Dermabond topical skin adhesive. Surg Infect (Larchmt) 3:251-257, 2002

11. Bible JE, Biswas D, Whang PG, Simpson AK, Grauer JN: Which regions of the operating gown should be considered most sterile? Clin Orthop Relat Res 467:825-830, 2009

12. Bible JE, O'Neill KR, Crosby CG, Schoenecker JG, McGirt MJ, Devin CJ: Microscope sterility during spine surgery. Spine (Phila Pa 1976) 37:623-627, 2012

13. Biswas D, Bible JE, Whang PG, Simpson AK, Grauer JN: Sterility of C-arm fluoroscopy during spinal surgery. Spine (Phila Pa 1976) 33:1913-1917, 2008

14. Blomstedt GC, Kyttä J: Results of a randomized trial of vancomycin prophylaxis in craniotomy. J Neurosurg 69:216-220, 1988

15. Bratzler DW, Houck PM: Antimicrobial prophylaxis for surgery: an advisory statement from the National Surgical Infection Prevention Project. Clin Infect Dis 38:1706-1715, 2004

16. Bratzler DW, Houck PM, Richards C, Steele L, Dellinger EP, Fry DE, et al: Use of antimicrobial prophylaxis for major surgery: baseline results from the National Surgical Infection Prevention Project. Arch Surg 140:174-182, 2005

17. Byrd JJ, Xu HS, Colwell RR: Viable but nonculturable bacteria in drinking water. Appl Environ Microbiol 57:875-878, 1991

18. Classen DC, Evans RS, Pestotnik SL, Horn SD, Menlove RL, Burke JP: The timing of prophylactic administration of antibiotics and the risk of surgical-wound infection. N Engl J Med 326:281-286, 1992

19. Cronquist AB, Jakob K, Lai L, Della Latta P, Larson EL: Relationship between skin microbial counts and surgical site infection after neurosurgery. Clin Infect Dis 33:1302-1308, 2001
20. Daly JM, Reynolds J, Thom A, Kinsley L, Dietrick-Gallagher $\mathrm{M}$, Shou J, et al: Immune and metabolic effects of arginine in the surgical patient. Ann Surg 208:512-523, 1988

21. Darouiche RO, Wall MJ Jr, Itani KMF, Otterson MF, Webb AL, Carrick MM, et al: Chlorhexidine-alcohol versus povidone-iodine for surgical-site antisepsis. N Engl J Med 362:18-26, 2010

22. Edwards PS, Lipp A, Holmes A: Preoperative skin antiseptics for preventing surgical wound infections after clean surgery. Cochrane Database Syst Rev (3):CD003949, 2004

23. Epstein NE: Do silver-impregnated dressings limit infections after lumbar laminectomy with instrumented fusion? Surg Neurol 68:483-485, 2007

24. Evans HL, Dellit TH, Chan J, Nathens AB, Maier RV, Cuschieri J: Effect of chlorhexidine whole-body bathing on hospital-acquired infections among trauma patients. Arch Surg 145:240-246, 2010

25. Evans RP: Current concepts for clean air and total joint arthroplasty: laminar airflow and ultraviolet radiation: a systematic review. Clin Orthop Relat Res 469:945-953, 2011

26. Furnary AP, Zerr KJ, Grunkemeier GL, Starr A: Continuous intravenous insulin infusion reduces the incidence of deep sternal wound infection in diabetic patients after cardiac surgical procedures. Ann Thorac Surg 67:352-362, 1999

27. Gabig TG, Bearman SI, Babior BM: Effects of oxygen tension and $\mathrm{pH}$ on the respiratory burst of human neutrophils. Blood 53:1133-1139, 1979

28. Gallacher SJ, Thomson G, Fraser WD, Fisher BM, Gemmell CG, MacCuish AC: Neutrophil bactericidal function in diabetes mellitus: evidence for association with blood glucose control. Diabet Med 12:916-920, 1995

29. Graffagnino C, Gurram AR, Kolls B, Olson DM: Intensive insulin therapy in the neurocritical care setting is associated with poor clinical outcomes. Neurocrit Care 13:307-312, 2010

30. Grap MJ, Munro CL, Elswick RK Jr, Sessler CN, Ward KR: Duration of action of a single, early oral application of chlorhexidine on oral microbial flora in mechanically ventilated patients: a pilot study. Heart Lung 33:83-91, 2004

31. Greene KA, Wilde AH, Stulberg BN: Preoperative nutritional status of total joint patients. Relationship to postoperative wound complications. J Arthroplasty 6:321-325, 1991

32. Greif R, Akça O, Horn EP, Kurz A, Sessler DI: Supplemental perioperative oxygen to reduce the incidence of surgicalwound infection. N Engl J Med 342:161-167, 2000

33. Gruskay J, Kepler C, Smith J, Radcliff K, Vaccaro A: Is surgical case order associated with increased infection rate after spine surgery? Spine (Phila Pa 1976) 37:1170-1174, 2012

34. Guest JD, Vanni S, Silbert L: Mild hypothermia, blood loss and complications in elective spinal surgery. Spine J 4:130137,2004

35. Guo YP, Wong PM, Li Y, Or PPL: Is double-gloving really protective? A comparison between the glove perforation rate among perioperative nurses with single and double gloves during surgery. Am J Surg 204:210-215, 2012

36. Hall LT, Bailes JE: Using Dermabond for wound closure in lumbar and cervical neurosurgical procedures. Neurosurgery 56 (1 Suppl):147-150, 2005

37. Harbarth S, Samore MH, Lichtenberg D, Carmeli Y: Prolonged antibiotic prophylaxis after cardiovascular surgery and its effect on surgical site infections and antimicrobial resistance. Circulation 101:2916-2921, 2000

38. Hardy SJ, Nowacki AS, Bertin M, Weil RJ: Absence of an association between glucose levels and surgical site infections in patients undergoing craniotomies for brain tumors. Clinical article. J Neurosurg 113:161-166, 2010

39. Harjula A, Järvinen A: Postoperative median sternotomy dehiscence. Scand J Thorac Cardiovasc Surg 17:277-281, 1983

40. Hassinger SM, Harding G, Wongworawat MD: High-pressure pulsatile lavage propagates bacteria into soft tissue. Clin Orthop Relat Res 439:27-31, 2005 
41. Haynes AB, Weiser TG, Berry WR, Lipsitz SR, Breizat AHS, Dellinger EP, et al: A surgical safety checklist to reduce morbidity and mortality in a global population. N Engl J Med 360:491-499, 2009

42. Herman LG: Sources of the slow-growing pigmented water bacteria. Health Lab Sci 13:5-10, 1976

43. Hughes MA, Parisi M, Grossman S, Kleinberg L: Primary brain tumors treated with steroids and radiotherapy: low CD4 counts and risk of infection. Int J Radiat Oncol Biol Phys 62: 1423-1426, 2005

44. Jenkins S, Addy M, Wade W: The mechanism of action of chlorhexidine. A study of plaque growth on enamel inserts in vivo. J Clin Periodontol 15:415-424, 1988

45. Kirby WM, Regamey C: Pharmacokinetics of cefazolin compared with four other cephalosporins. J Infect Dis 128:S341S346, 1973

46. Kirk SJ, Hurson M, Regan MC, Holt DR, Wasserkrug HL, Barbul A: Arginine stimulates wound healing and immune function in elderly human beings. Surgery 114:155-160, 1993

47. Klein JD, Garfin SR: Nutritional status in the patient with spinal infection. Orthop Clin North Am 27:33-36, 1996

48. Kumar K, Crawford AH: Role of "Bovie" in spinal surgery: historical and analytical perspective. Spine (Phila Pa 1976) 27:1000-1006, 2002

49. Kurz A, Sessler DI, Lenhardt R: Perioperative normothermia to reduce the incidence of surgical-wound infection and shorten hospitalization. N Engl J Med 334:1209-1215, 1996

50. Leslie-Mazwi TM, Sims JR, Hirsch JA, Nogueira RG: Periprocedural blood pressure management in neurointerventional surgery. J Neurointerv Surg 3:66-73, 2011

51. Levitt MR, Gabikian P, Pottinger PS, Silbergeld DL: Propionibacterium acnes osteomyelitis occurring 23 years after craniotomy: case report and review of literature. Neurosurgery 69:E773-E779, 2011

52. Lidwell OM, Elson RA, Lowbury EJL, Whyte W, Blowers R, Stanley SJ, et al: Ultraclean air and antibiotics for prevention of postoperative infection. A multicenter study of 8,052 joint replacement operations. Acta Orthop Scand 58:4-13, 1987

53. Lidwell OM, Lowbury EJ, Whyte W, Blowers R, Stanley SJ, Lowe D: Effect of ultraclean air in operating rooms on deep sepsis in the joint after total hip or knee replacement: a randomised study. Br Med J (Clin Res Ed) 285:10-14, 1982

54. Lopez M, Sessler DI, Walter K, Emerick T, Ozaki M: Rate and gender dependence of the sweating, vasoconstriction, and shivering thresholds in humans. Anesthesiology 80:780-788, 1994

55. Losanoff JE, Richman BW, Jones JW: Disruption and infection of median sternotomy: a comprehensive review. Eur J Cardiothorac Surg 21:831-839, 2002

56. Mack D, Fischer W, Krokotsch A, Leopold K, Hartmann R, Egge H, et al: The intercellular adhesin involved in biofilm accumulation of Staphylococcus epidermidis is a linear beta-1,6-linked glucosaminoglycan: purification and structural analysis. J Bacteriol 178:175-183, 1996

57. Magyar CE, Aghaloo TL, Atti E, Tetradis S: Ostene, a new alkylene oxide copolymer bone hemostatic material, does not inhibit bone healing. Neurosurgery 63 (4 Suppl 2):373-378, 2008

58. Manz W, Szewzyk U, Ericsson P, Amann R, Schleifer KH, Stenström TA: In situ identification of bacteria in drinking water and adjoining biofilms by hybridization with $16 \mathrm{~S}$ and 23S rRNA-directed fluorescent oligonucleotide probes. Appl Environ Microbiol 59:2293-2298, 1993

59. Matzke GR, Zhanel GG, Guay DR: Clinical pharmacokinetics of vancomycin. Clin Pharmacokinet 11:257-282, 1986

60. McPhee IB, Williams RP, Swanson CE: Factors influencing wound healing after surgery for metastatic disease of the spine. Spine 23:726-733, 1998

61. Mehta AI, Babu R, Karikari IO, Grunch B, Agarwal VJ, Ow- ens TR, et al: 2012 Young Investigator Award Winner: The distribution of body mass as a significant risk factor for lumbar spinal fusion postoperative infections. Spine (Phila Pa 1976) $37: 1652-1656,2012$

62. Mekalanos JJ: Environmental signals controlling expression of virulence determinants in bacteria. J Bacteriol 174:1-7, 1992

63. Miller JP, Acar F, Burchiel KJ: Significant reduction in stereotactic and functional neurosurgical hardware infection after local neomycin/polymyxin application. Clinical article. J Neurosurg 110:247-250, 2009

64. Miller MB, Bassler BL: Quorum sensing in bacteria. Annu Rev Microbiol 55:165-199, 2001

65. Montagna W: The Structure and Function of Skin, ed 2. New York: Academic Press, 1962

66. Nakamura K, Kariyazono H, Komokata T, Hamada N, Sakata $\mathrm{R}$, Yamada K: Influence of preoperative administration of $\omega-3$ fatty acid-enriched supplement on inflammatory and immune responses in patients undergoing major surgery for cancer. Nutrition 21:639-649, 2005

67. Nishida H, Grooters RK, Soltanzadeh H, Thieman KC, Schneider RF, Kim WP: Discriminate use of electrocautery on the median sternotomy incision. A $0.16 \%$ wound infection rate. Discussion J Thorac Cardiovasc Surg 101:488-494, 1991

68. Nornes H, Knutzen HB, Wikeby P: Cerebral arterial blood flow and aneurysm surgery. Part 2: Induced hypotension and autoregulatory capacity. J Neurosurg 47:819-827, 1977

69. Parienti JJ, Thibon P, Heller R, Le Roux Y, von Theobald P, Bensadoun $\mathrm{H}$, et al: Hand-rubbing with an aqueous alcoholic solution vs traditional surgical hand-scrubbing and 30-day surgical site infection rates: a randomized equivalence study. JAMA 288:722-727, 2002 (Erratum in JAMA 288:2689, 2002)

70. Perley M, Kipnis DM: Effect of glucocorticoids on plasma insulin. N Engl J Med 274:1237-1241, 1966

71. Perner A, Nielsen SE, Rask-Madsen J: High glucose impairs superoxide production from isolated blood neutrophils. Intensive Care Med 29:642-645, 2003

72. Pople IK, Bayston R, Hayward RD: Infection of cerebrospinal fluid shunts in infants: a study of etiological factors. J Neurosurg 77:29-36, 1992

73. Porter KA, O'Connor S, Rimm E, Lopez M: Electrocautery as a factor in seroma formation following mastectomy. Am J Surg 176:8-11, 1998

74. Proctor LM: The human microbiome project in 2011 and beyond. Cell Host Microbe 10:287-291, 2011

75. Pryor KO, Fahey TJ III, Lien CA, Goldstein PA: Surgical site infection and the routine use of perioperative hyperoxia in a general surgical population: a randomized controlled trial. JAMA 291:79-87, 2004

76. Puig-Kröger A, Pello OM, Selgas R, Criado G, Bajo MA, Sánchez-Tomero JA, et al: Peritoneal dialysis solutions inhibit the differentiation and maturation of human monocyte-derived dendritic cells: effect of lactate and glucose-degradation products. J Leukoc Biol 73:482-492, 2003 (Erratum in J Leukoc Biol 82:1605, 2007)

77. Reasoner DJ, Geldreich EE: A new medium for the enumeration and subculture of bacteria from potable water. Appl Environ Microbiol 49:1-7, 1985

78. Rhoton AL Jr: Operative techniques and instrumentation for neurosurgery. Neurosurgery 53:907-934, 2003

79. Roberts RR, Hota B, Ahmad I, Scott RD II, Foster SD, Abbasi F, et al: Hospital and societal costs of antimicrobial-resistant infections in a Chicago teaching hospital: implications for antibiotic stewardship. Clin Infect Dis 49:1175-1184, 2009

80. Sarlis NJ, Chanock SJ, Nieman LK: Cortisolemic indices predict severe infections in Cushing syndrome due to ectopic production of adrenocorticotropin. J Clin Endocrinol Metab 85:42-47, 2000 
81. Segers P, Speekenbrink RGH, Ubbink DT, van Ogtrop ML, de Mol BA: Prevention of nosocomial infection in cardiac surgery by decontamination of the nasopharynx and oropharynx with chlorhexidine gluconate: a randomized controlled trial. JAMA 296:2460-2466, 2006

82. Sessler DI, Rubinstein EH, Moayeri A: Physiologic responses to mild perianesthetic hypothermia in humans. Anesthesiology 75:594-610, 1991

83. Shiono Y, Watanabe K, Hosogane N, Tsuji T, Ishii K, Nakamura M, et al: Sterility of posterior elements of the spine in posterior correction surgery. Spine (Phila Pa 1976) 37:523526,2012

84. Singer AJ, Clark RA: Cutaneous wound healing. N Engl J Med 341:738-746, 1999

85. Smith GC, Pell JP: Parachute use to prevent death and major trauma related to gravitational challenge: systematic review of randomised controlled trials. BMJ 327:1459-1461, 2003

86. Snyderman CH, Kachman K, Molseed L, Wagner R, D’Amico F, Bumpous J, et al: Reduced postoperative infections with an immune-enhancing nutritional supplement. Laryngoscope 109:915-921, 1999

87. Soballe PW, Nimbkar NV, Hayward I, Nielsen TB, Drucker WR: Electric cautery lowers the contamination threshold for infection of laparotomies. Am J Surg 175:263-266, 1998

88. St Jacques P, Sanders N, Patel N, Talbot TR, Deshpande JK, Higgins M: Improving timely surgical antibiotic prophylaxis redosing administration using computerized record prompts. Surg Infect (Larchmt) 6:215-221, 2005

89. Still CD, Benotti P, Wood GC, Gerhard GS, Petrick A, Reed $\mathrm{M}$, et al: Outcomes of preoperative weight loss in high-risk patients undergoing gastric bypass surgery. Arch Surg 142: 994-999, 2007

90. Stocks GW, Self SD, Thompson B, Adame XA, O'Connor DP: Predicting bacterial populations based on airborne particulates: a study performed in nonlaminar flow operating rooms during joint arthroplasty surgery. Am J Infect Control 38:199-204, 2010

91. Stranc MF, McDiarmid JG, Stranc LC: Video assessment of surgical technique. Br J Plast Surg 44:65-68, 1991

92. Tanner J, Parkinson H: Double gloving to reduce surgical cross-infection. Cochrane Database Syst Rev (3):CD003087, 2006

93. Tanner J, Swarbrook S, Stuart J: Surgical hand antisepsis to reduce surgical site infection. Cochrane Database Syst Rev (1):CD004288, 2008

94. Tanner J, Woodings D, Moncaster K: Preoperative hair removal to reduce surgical site infection. Cochrane Database Syst Rev (3):CD004122, 2006

95. Tepaske R, Velthuis H, Oudemans-van Straaten HM, Heisterkamp SH, van Deventer SJH, Ince C, et al: Effect of preoperative oral immune-enhancing nutritional supplement on patients at high risk of infection after cardiac surgery: a randomised placebo-controlled trial. Lancet 358:696-701, 2001
96. Todd MM, Hindman BJ, Clarke WR, Torner JC: Mild intraoperative hypothermia during surgery for intracranial aneurysm. N Engl J Med 352:135-145, 2005

97. Toma O, Suntrup P, Stefanescu A, London A, Mutch M, Kharasch E: Pharmacokinetics and tissue penetration of cefoxitin in obesity: implications for risk of surgical site infection. Anesth Analg 113:730-737, 2011

98. Walsh TJ, Mendelsohn G: Invasive aspergillosis complicating Cushing's syndrome. Arch Intern Med 141:1227-1228, 1981

99. Weaver DD, inventor; MegaDyne Medical Products, Inc, assignee: Coated bipolar electrocautery. US patent 5,693,052. December 2, 1997

100. Webster J, Alghamdi AA: Use of plastic adhesive drapes during surgery for preventing surgical site infection. Cochrane Database Syst Rev (4):CD006353, 2007

101. Webster J, Osborne S: Preoperative bathing or showering with skin antiseptics to prevent surgical site infection. Cochrane Database Syst Rev (2):CD004985, 2006

102. Weiner BK, Kilgore WB: Bacterial shedding in common spine surgical procedures: headlamp/loupes and the operative microscope. Spine (Phila Pa 1976) 32:918-920, 2007

103. Wellisz T, Armstrong JK, Cambridge J, Fisher TC: Ostene, a new water-soluble bone hemostasis agent. J Craniofac Surg 17:420-425, 2006

104. Winston KR: Hair and neurosurgery. Neurosurgery 31:320 329, 1992

105. Winston KR, McBride LA, Dudekula A: Bandages, dressings, and cranial neurosurgery. J Neurosurg 106 (6 Suppl):450454, 2007

106. Wolcott RD, Gontcharova V, Sun Y, Zischakau A, Dowd SE: Bacterial diversity in surgical site infections: not just aerobic cocci any more. J Wound Care 18:317-323, 2009

107. Zanetti G, Flanagan HL Jr, Cohn LH, Giardina R, Platt R: Improvement of intraoperative antibiotic prophylaxis in prolonged cardiac surgery by automated alerts in the operating room. Infect Control Hosp Epidemiol 24:13-16, 2003

108. Zanetti G, Giardina R, Platt R: Intraoperative redosing of cefazolin and risk for surgical site infection in cardiac surgery. Emerg Infect Dis 7:828-831, 2001

109. Zeh A, Messer J, Davis J, Vasarhelyi A, Wohlrab D: The Aquamantys system - an alternative to reduce blood loss in primary total hip arthroplasty? J Arthroplasty 25:10721077,2010

Manuscript submitted July 12, 2012.

Accepted August 30, 2012.

Please include this information when citing this paper: DOI: 10.3171/2012.8.FOCUS12245.

Address correspondence to: Brian P. Walcott, M.D., Massachusetts General Hospital, 55 Fruit Street, White Building Room 502, Massachusetts General Hospital, Boston, Massachusetts 02114. email: walcott.brian@mgh.harvard.edu. 